\title{
Design, mercados e negócios: Uma revisão de literatura
}

\author{
Camila Ferreira Santos ${ }^{1}$; \\ Wener Miranda Teixeira dos Santos;
}

resumo:

Conhecer as contribuições de cada área para um projeto em Design, implica na adaptação de assuntos correlatos e ajustes para cada tipo de situação, e é exatamente por este motivo, em que inserir o próprio design na área de gestão, pode apresentar mudanças significativas e ao mesmo tempo complexa de ser assimilado, sobretudo para quem o vê apenas como sinônimo de diferencial em um modo produtivo, seja um projeto de produto, ou gráfico, ou em algum propósito similar.

Para que haja uma maior compreensão da contribuição do Design como possível aporte no gerenciamento e em melhorias nos negócios, busca-se fazer uma reflexão baseada em conceitos característicos que ajudam na percepção e na disseminação desta área de conhecimento. Este artigo tem como propósito reunir pesquisadores que exploram fragmentos entre as relações do Design e o meio social. Através de uma breve revisão de literatura apresenta-se a seguinte questão: Como o design vem sendo incorporado no universo corporativo?

palavras-chave:

Design; gerenciamento; melhorias nos negócios; revisão de literatura; meio social.

Espaço reservado para organização do congresso.

\footnotetext{
${ }^{1}$ http://lattes.cnpq.br/7536417736485312

2 http://lattes.cnpq.br/4420573225279073
} 


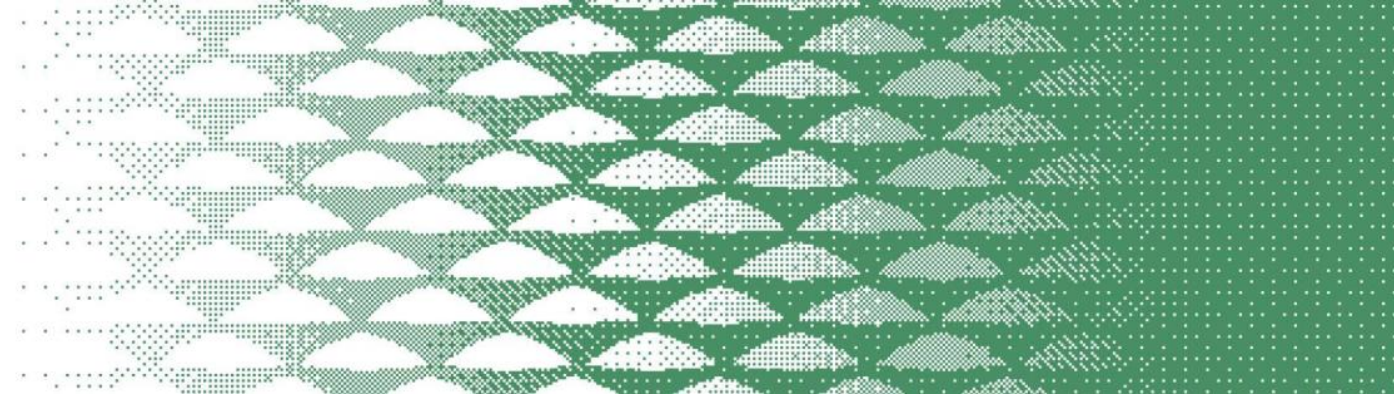

\section{Design: Mercados e Negócios}

Desde os primórdios dos tempos, o homem em sua natureza trabalha como forma de sobrevivência estabelecendo uma relação entre transformação de bens e valores, tal atividade é um fenômeno necessário do qual sempre estará presente em seu cotidiano (FILHO, p. 22, 1994), no entanto, as transformações sociais podem afetar o modo em que esta ação está sendo desempenhada, o que permite a evolução de novas configurações de trabalho.

Em um contexto contemporâneo, temas como crises econômicas e financeiras, altos índices de desemprego, têm se mostrado cada vez mais frequentes. Em pesquisa recente do site Correio Braziliense, jovens pertencentes à comunidade acadêmica brasileira têm-se mostrado inquietos em relação à empregabilidade durante e pós conclusão de curso superior (LISBOA, 2018), tal acontecimento tem induzido um cenário de mudanças, onde à atitude inovadora se mostra a marca registrada de novos profissionais, empreendedores, executivos e líderes.

Ao buscar por novas oportunidades depara-se com uma geração dinâmica que usufrui das possibilidades e lacunas que tal mercado apresenta, isso quer dizer que todo este movimento de faltas de circunstâncias oportunas acarreta em pessoas que acrescentam vivência, experiências e propósitos pessoais em possíveis negócios, atribuindo no empreendedorismo práticas com soluções aplicadas de maneira rápida a fim de moldar-se às mudanças que possam vir a surgir (ALBUQUERQUE, p. 95, 2016).

Vazquez apresentou à revista digital E-commerce Brasil em julho de 2021 que as pessoas veem no empreendedorismo um acesso em busca de atender as suas necessidades, mas também de apresentar mudanças em suas áreas de atuação, desta maneira, as transformações no modo de oferecer produtos e serviços se tornam por adaptações e novas propostas de resoluções para as adversidades de um mundo em constante mudança. (VAZQUEZ, 2021).

De acordo com Palmer e Blake (p. 179, 2019) existem certas habilidades que devem ser características essenciais no desenvolvimento das carreiras profissionais do futuro, estas identificadas através de três áreas-chave que embora subjetivas mostram forte relevância comparando inclusive ao avanço de novas tecnologias. A primeira área está relacionada à estrutura e aperfeiçoamento de ideias e uso da criatividade; a segunda refere-se ao estímulo de empatia e habilidades humanas; a terceira atribui à agilidade e flexibilidade do desenvolvimento mental.

Tal desdobramento pode ser direcionado a construção de uma nova realidade e também se relaciona à área em que o profissional designer está sendo alocado. De acordo com Albuquerque (p. 100, 2016), o designer do futuro poderá desenvolver competências que o permitirá elaborar estratégias de negócios por intermédio dos modelos tradicionais, configurar ferramentas através de modelos mentais e projetos multidisciplinares a fim de buscar resoluções para os problemas de maneira mais eficaz e então aplicar constantemente em formas inovadoras, agregando valor e significado em negócios, marcas consistentes e serviços diferenciados.

Ao fazer uma análise nas relações entre empresas e consumidores e/ou usuários até um tempo atrás resumia-se apenas em trocas de produtos e serviços por um valor monetário, no entanto, em dias atuais isto vai muito além, o empreendedor que proporciona novas experiências conquista diferentes 




públicos, ganha novos espaços e cria conexões onde está inserido, não apenas com clientes, mas com todos os envolvidos no processo (stakeholders).

Nesse contexto o design pode ser introduzido como um importante aliado, tendo em vista que este objetiva unir inovação aos processos, integrando fatores externos e internos as metas do negócio, desta forma a gestão inserida por viés do design nas empresas integra os recursos produtivos aos objetivos da organização. Abaixo apresenta-se quadro que demonstra os níveis do design, nas mais variadas esferas a partir da visão de Albuquerque (2016).

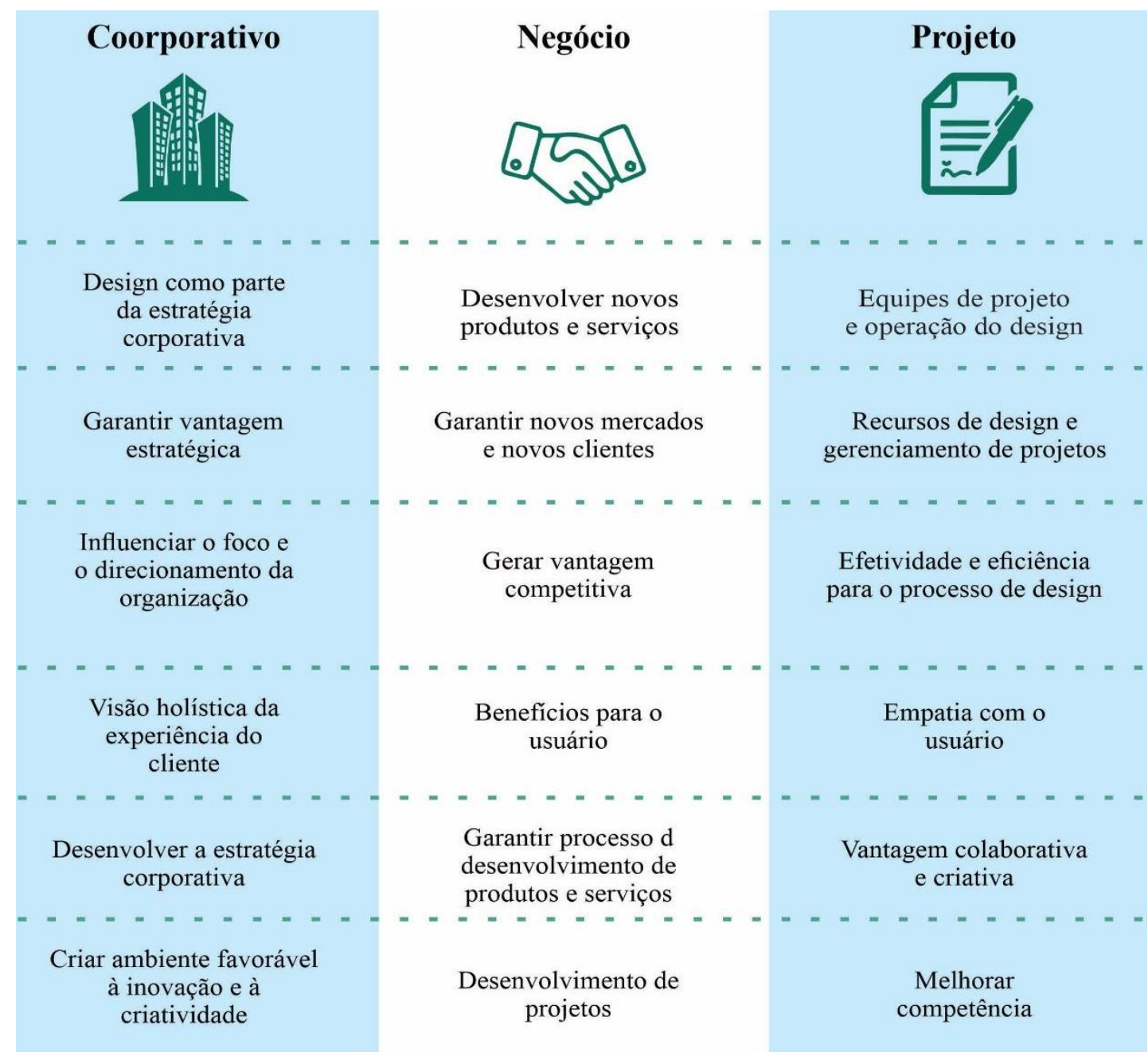

Quadro 1 Nível do design a partir da atuação nas empresas

Fonte: Albuquerque (2016). Adaptado por autores (2021).

Como apontado no quadro, o design aparece em diferentes configurações a partir de sua aplicação dentro do universo empresarial, e isto implica em concepções e construção de projeto em design por outras percepções, obtendo também novas propostas e outras resoluções. Dado tal levantamento faz-se necessário salientar alguns pontos considerados pertinentes do campo da administração na qual envolve o planejamento de negócios junto ao empreendedorismo. 


\subsection{Relações histórico comerciais}

A compreensão para uma mudança de cenário dentro do campo empresarial, permeia por um contexto histórico, onde antes se obtinha um mercado com características bem estruturadas, desta forma, Moraes (2010) apresenta como um cenário estático, formado por uma rede ordenada na qual era apresentada através de uma certa previsibilidade criada por conta de um comportamento de entendimento do consumidor ao produto, assim, designers e produtores detinham de aparatos para que traduzisse e interpretasse os desejos de quem pudesse consumir ou usar cada produto.

Nos dias de hoje, no entanto, com o avanço das próprias tecnologias, e novas concepções de pensamentos contemporâneos, a linearidade na produção já não satisfaz a maioria, pelo contrário, surge então uma movimentação decorrente inclusive aos processos de comunicação, como internet e redes sociais, que conectam pequenos grupos e os diferenciam em uma escala global, ou seja, se antes era necessário que um produto tivesse um certo tempo para chegar ao ápice de escolhas do usuário, este tempo hoje, encontra-se reduzido por meio da rápida informação obtida e feedbacks de usuários que trocam rapidamente de ideias. Como consequência Branzi (2006) declara que há um ambiente que é de fato diversificado e oposto, porém relacionam-se em um mesmo instante.

A partir desse contexto, o design se mostra através de um novo parâmetro e abre espaço para uma nova aplicabilidade, a possibilidade da incorporação de personalização, isto é o que aproxima a empresa contemporânea de seus respectivos públicos, Franzato (2010) defende que este processo aprimora a semântica de objetos ao seu significado. Para Celaschi (2007) a relação que o design tem para com o mercado e consumidor, passa então a estar interligado diretamente com o modo em que estas convivem e se relacionam, sendo assim o design não é só visto como uma parte dos negócios e sim íntegra viabilidades técnicas e produtivas, aos valores de troca, uso e relacional dentro da cadeia de valor.

De acordo com Moraes (2010) o design pode ser adotado como um instrumento estratégico, tendo em vista sua capacidade em evidenciar problemas e gerenciar através de sua complexidade, pois o cenário então construído é codificado, dinâmico e de difícil compreensão, isto implica dizer que a capacidade do profissional deve ser mais que apenas projetual, deve ser de constante atualização e propenso à gestão dessa complexidade. Através desta, e a partir da frequente mudança de pensamento cultural faz-se necessário repensar como pode dar-se a concepção de projetar design compreendendo processos, valores, usuários como parte de um processo.

A esta dinâmica, dar-se um novo conceito chamado de metaprojeto, este se define através da construção de cenários distintos de aplicação, através da adoção de novas propostas ou análises corretivas em propostas existentes, de modo em que as atividades projetuais sejam compreendidas em sua totalidade, o profissional então se torna capaz de "traçar limites, analisar e, sobretudo, realizar uma síntese compreensível de cada etapa projetual”. (Moraes, 2010, p.21). Ainda de acordo com o autor, o objetivo do metaprojeto consiste em propiciar um cenário a partir de uma "plataforma de conhecimentos" (2010, p. 31), relacionando os pontos negativos e positivos, analisando o ciclo de vida, as tecnologias aplicáveis, recursos, fatores sociais e mercadológicos. Este é baseado de acordo estrutura apresentada na figura abaixo. 
Quadro 2 Estrutura disciplinar metaprojeto Fonte: Moraes (p. 33, 2010)

\subsection{Campo social e cultural versus Cenário econômico}

Segundo Marins (2006), conforme surgem a relação entre tecnologia e inovação dentro das empresas, há novas formas dentro da Economia para a análise desses processos, desta maneira que integra a gestão tecnológica à complexidade atual. De acordo com Manzini (2010) há um novo paradigma frente as mudanças econômicas, que são recorrentes as crises mundiais geradas pelas atividades oriundas desta e das próximas décadas, estas implicam em transformações na relação sistema de produção e consumo, além de concepções regionais para o desenvolvimento de uma forma coletiva e colaborativa, ainda, é através deste patamar que surgem as oportunidades.

O contexto do capitalismo contemporâneo então, dar-se através destas viabilidades oportunas, tendo em vista que cada momento em que há o surgimento de uma crise, as possibilidades de intervenção, também são variáveis, e neste quesito que novas formas de produção, produtos, serviços e outros tendem a substituir ao modelo vigente, $\operatorname{logo}$, a inovação aparece como projeção dinâmica do próprio capitalismo.

Seguindo ainda o mesmo contexto de ruptura de um modelo para outro, o design pode se apresentar como um importante instrumento de reflexão a partir de visões, propostas e ferramentas que estimulem discussões a fim de criar uma nova rede de compartilhamento de conhecimento, onde indivíduos, empresas e/ou organizações e instituições compartilham valores. Tal fator, pode ser destacado por Benkler (2009), como uma forma de reunir indivíduos que se unem através de um propósito em comum, isto é, a possibilidade da contribuição para determinado tema, tem a ver com, principalmente, a experiência cultural e com as mudanças oriundas a partir da colaboração de diferentes pontos de vista, o que pode gerar em uma melhora do modelo comercial em um todo.

Simon e Vieira (2007), afirmam que tal produção colaborativa há uma forte participação nas relações produtivas fora de uma estrutura de mercado. Então, analisar e avaliar os aspectos pessoais, implicam em uma compreensão mais rica perante o microempreendedor e o seu negócio, já que este é pautado, a partir de motivação pessoal ao engajamento profissional, tal participação dar-se através da implementação de ações que engajam e motivam usuários com várias possibilidades de resolução de um determinado caso, utilizando dos próprios meios e veículos de comunicação que o micro empresário utiliza, assim, ele cria uma rede de comunicação, na qual clientes, parceiros, terceirizados, são pertencentes a um mesmo ambiente. E é dentro deste cenário que pode ser previsto a influência de certas características como perfis e descrição de um mercado por uma rede de pessoas e das relações em que estas formam. 


\section{JOP DESIGN

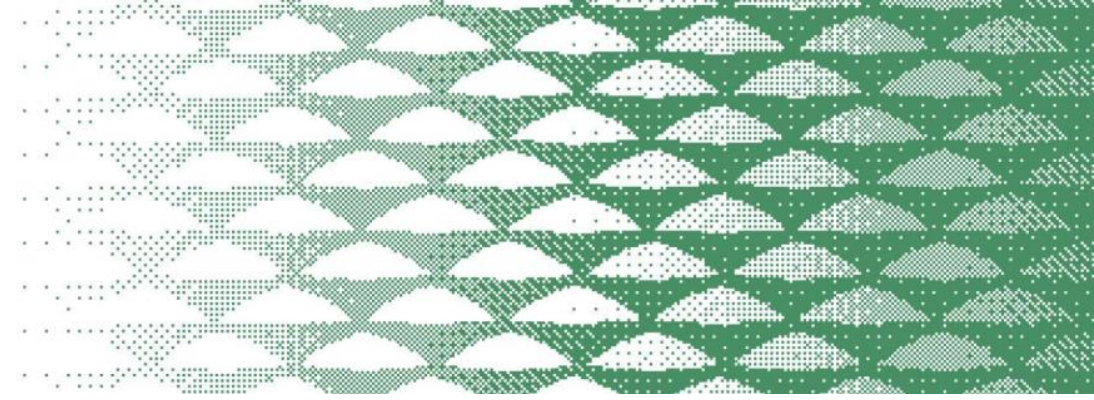

\subsection{Aspectos estratégicos de negócios}

O design como fator estratégico possui competências que permitem analisar e observar as situações propostas de forma ágil permitindo que alternativas sejam previamente abordadas com o intuito de acumular valor competitivo na empresa (Albuquerque, p. 101, 2016). Já o empreendedorismo está relacionado à oportunidade e as lacunas que determinado mercado pode sugerir (HISRICH; PETERS; SHEPHERD, p. 6, 2014). Primordialmente para compreender esta relação, design, mercado e empreendedorismo, faz-se necessário detectar os pontos que desencadearam as transformações nos negócios e o funcionamento de empresas de forma tradicional pautados na administração, tendo em vista que essa continua sendo, e mesmo com o avanço das pesquisas de áreas afins que contribuem no seu gerenciamento, a maneira mais usual de conduzir os interesses das companhias.

Veja no quadro a seguir as percepções e diferenças na gestão a partir de sua visão cultural quando empregada em uma organização funcional e/ou tradicional e quando é voltada a cultura do design.

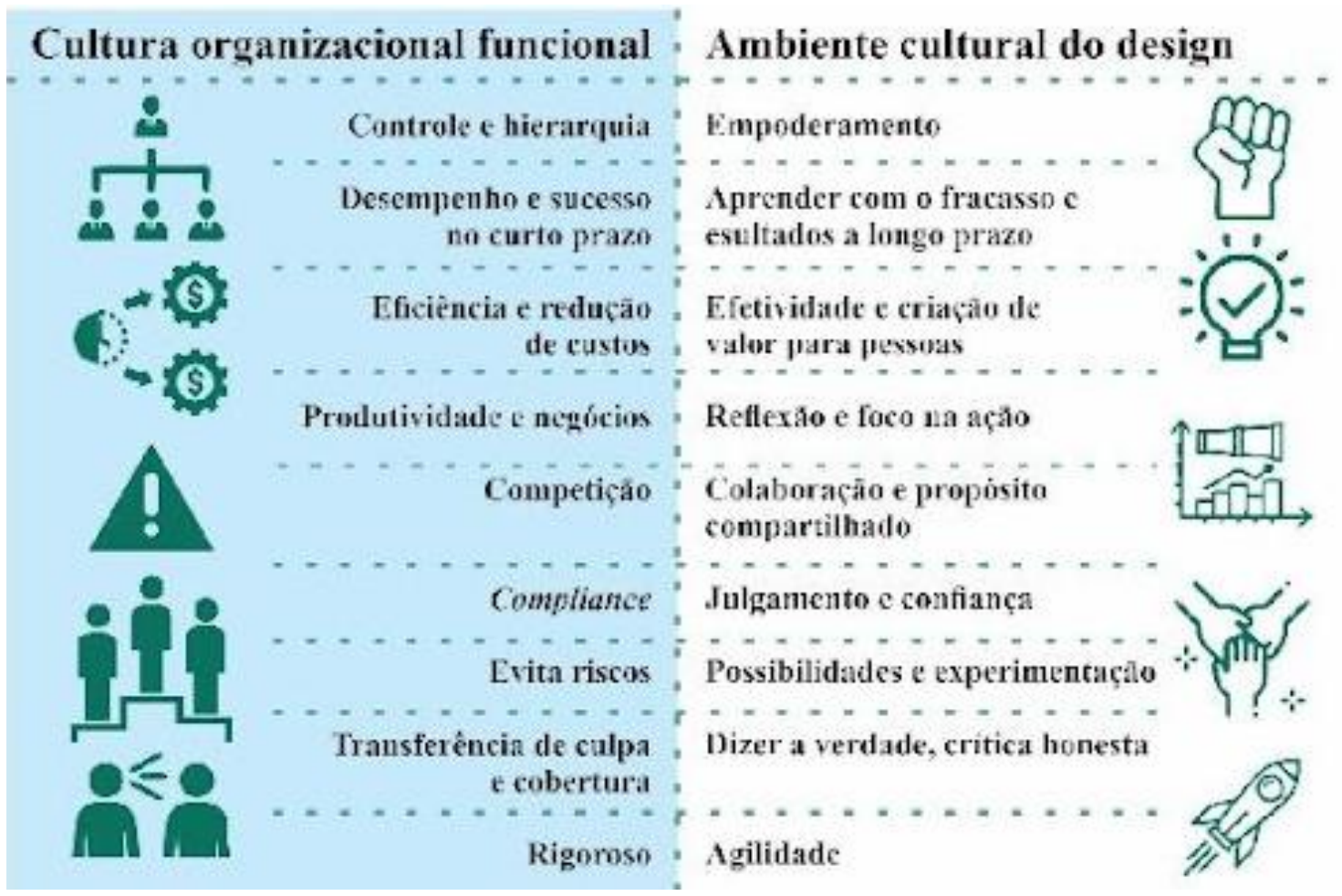

Quadro 3 Diferenças da gestão com culturas tradicionais e cultura em design Fonte: Albuquerque (2016). Adaptado por autores (2021).

"O Brasil registrou 1,2 milhão de novas empresas no primeiro semestre de 2018, o maior número para o período desde 2010" (E-COMMERCE BRASIL, 2018). Este número reflete não só ações de pessoas com mentalidade empreendedora, mas está associado também à fatores que contribuem diretamente no novo jeito de se "fazer negócio". Tal dados, tiveram mudanças abruptas desde 2020 por conta da pandemia mundial causada pela COVID-19. No entanto, as causas primárias relacionadas a este cenário estão diretamente ligadas a três aspectos essenciais no ponto de vista das transformações sociais contemporâneas. 




Nesse parâmetro o design como estratégia mostra-se como um campo que dispõe da geração de conceitos para o que está em foco projetual, assim como traz agilidade e assertividade em ações que estão sendo estudadas ou desenvolvidas, combinando processos e presteza nas mudanças internas e externas a fim de promover inovação de forma colaborativa, empática entregando sobretudo valor. (ALBUQUERQUE, p. 98, 2016).

A interdisciplinaridade da área do design estratégico permeia entre os níveis de atuação que uma empresa pode desenvolver. $\mathrm{O}$ design pode estar agregado à estratégia corporativa, na elaboração de produtos e serviço, e também no nível operacional; a diferenciação dessas estão no resultado almejado para cada objetivo. Albuquerque (p. 99, 2016) afirma que quando as instituições assumem o mindset do design em suas práticas, estas acabam pela vantagem competitiva em relação a aquelas que pautam-se na gestão tradicional.

Tal predisposição resulta em mudanças culturais dentro da organização, onde antes se via setores separados pela hierarquia de cargos por exemplo, neste momento observa-se um empoderamento de cada profissional dentro do processo, isto pois agora este indivíduo faz parte do processo de forma colaborativa, a partir deste momento temos um profissional envolvido em diversos e relevantes campos do conhecimento dentro de sua formação. As especializações adquiridas aqui podem prever um empreendedor com foco em inovações, este então desdobra-se nas estratégias de negócio e de criação, dissociando modelos tradicionais, conectando-se às tendências, impactando nos resultados gerados agora reunido por uma equipe de profissionais multidisciplinares.

\section{Design, Markets and Business: A Literature Review}

Abstract: Knowing the contributions of each area to a project in Design implies the adaptation of related issues and adjustments for each type of situation, and it is precisely for this reason that inserting design itself in the management area can present significant changes and complex to be assimilated, especially for those who see it only as a synonym for a differential in a productive mode, be it a product design, or graphic design, or some similar purpose.

In order to have a greater understanding of the contribution of Design as a possible contribution to management and improvements in business, we seek to reflect on characteristic concepts that help in the perception and dissemination of this area of knowledge. This article aims to bring together researchers who explore fragments between the relations of Design and the social environment. Through a brief literature review, the following question is presented: How has design been incorporated into the corporate world? 


\section{Referências bibliográficas}

ALBUQUERQUE, Francisco. Design estratégico, inovação e empreendedorismo. In: MEGIDO, Victor Falasca. A revolução do design conexões para o século XXI. São Paulo: Gente, 2016.

BENKLER, Yochai. Saber comum: produção de materiais educacionais entre pare. FACED, Salvador, Bahia, n. 15, p. 13-46, 15 jan. 2009. Disponível em:

https://portalseer.ufba.br/index.php/entreideias/article/viewFile/3649/3517. Acesso em: 27 dez. 2019. BRANZI, A. Modernità debole e difusa: il mondo del progetto all'inizio del XXI secolo. Milano: Ed. Skira, 2006.

CELASCHI, F. DESSERTI, A. Design e Inovvazione, strumenti e pratiche per la ricerca applicata. Milano; Carocci, 2007. 148 p.

DORF, Bob; BLANK, Steve. Startup: Manual do Empreendedor: 0 guia passo a passo para construir uma grande empresa. Rio de Janeiro: Alta Books, 2014.

ECOMMERCE. Novas empresas no Brasil. 2018. Disponível em:

$<$ https://www.ecommercebrasil.com.br/noticias/brasil-recorde-abertura-empresas-primeiro-semestre2018/>. Acesso em: 11 de abr. 2021.

FILHO, Rubens Migliaccio. Reflexões sobre o homem e o trabalho. Revista de Administração de Empresa, São Paulo, 1994. Disponível em: http://www.scielo.br/pdf/rae/v34n2/a04v34n2.pdf. Acesso em: 24 abr. 2021.

FRANZATO, C. 0 processo de inovação dirigida pelo design. Um modelo teórico. Redige, v. 2, n. 1, 2011, p. 50-62. Disponível em:

http://www.cetiqt.senai.br/ead/redige/index.php/redige/article/viewArticle/72. Acesso em: 05 jan. 2020.

HISRICH, Robert; PETERS, Michael; SHEPHERD, Dean. Empreendedorismo. Porto Alegre: AMGH, 2014.

LISBOA, Ana Paula. Após sair da faculdade, recém-formados enfrentam desemprego e subemprego. 17 de ago. de 2018. Disponível em:

$<$ https://www.correiobraziliense.com.br/app/noticia/eu-

estudante/tf_carreira/2018/06/17/tf_carreira_interna,689082/apos-sair-da-faculdade-recem-formadosenfrentam-desemprego-e-subempre.shtml>. Acesso em: 28 de abr. 2021.

MANZINI, Ezio; JÉGOU, François. Design degli Scenari. In BERTOLA, Paola; MANZINI, Ezio (org.)

Design multiverso: appunti di fenomenologia del design. Milano: POLIdesign Edizioni, 2004.

MARINS, Luciana M. Economia, Tecnologia e Inovação: da Teoria da Firma à Gestão da Inovação Tecnológica. 300. Encontro da ANPAD. Salvador: 23 a 27 de setembro de 2006.

MORAES, D. Metaprojeto: O design do design. São Paulo: Blucher, 2010. 228 p.

PALMER, Kelly; BLAKE, David. Expertise Competitiva - Como as empresas mais inteligentes usam o aprendizado para engajar, competir e ter sucesso. Rio de Janeiro: Alta Books, 2019.

SEBRAE. Tudo o que você precisa saber para criar o seu plano de negócio. 2021. Disponível em: <http://www.sebrae.com.br/sites/PortalSebrae/artigos/como-elaborar-um-plano-denegocio,37d2438af1c92410VgnVCM100000b272010aRCRD>. Acesso em: 02 de abr. 2021.

SIMON, Imre; e VIEIRA, Miguel Said. A Propriedade Intelectual diante da emergência da produção social. IN: VILLARES, F. (Org). Propriedade Intelectual: tensões entre o capital e a sociedade. São Paulo: Paz e Terra, 2007.

VAZQUEZ, Alejandro. Empreender: único caminho para milhares de brasileiros. E-commmerce Brasil, [S. I.], p. -, 29 jul. 2021. Disponível em: https://www.ecommercebrasil.com.br/artigos/empreenderunico-caminho-para-milhares-de-brasileiros/. Acesso em: 3 ago. 2021. 